\title{
Morphologic characterisation of the posterior inferior cerebellar artery. A direct anatomic study
}

\author{
L.E. Ballesteros-Acuña1 ${ }^{1}$ H.Y. Estupiñán ${ }^{1,2}$, F.A. Gómez-Torres' ${ }^{10}$ \\ ${ }^{1}$ Department of Basic Sciences, Medicine School, Universidad Industrial de Santander, Bucaramanga, Colombia \\ ${ }^{2}$ Department of Laboratory Medicine, Clinical Research Centre, Karolinska Institute, Karolinska University Hospital \\ Huddinge, Huddinge, Sweden
}

[Received: 25 March 2021; Accepted: 26 April 2021; Early publication date: 29 June 2021]

Background: The number of studies on the cerebellar arteries has increased. The purpose of this study was to determine the morphological expression of posterior inferior cerebellar artery in a sample of Colombian population.

Materials and methods: One hundred eighty-six posterior inferior cerebellar arteries of fresh cadavers were studied. In each specimen, vertebral arteries were injected with $100 \mathrm{~mL}$ of semi-synthetic resin, dyed with mineral red.

Results: In the 93 blocks of brainstem and cerebellum evaluated, 174 (93.5\%) posterior inferior cerebellar arteries were found. Also, there were $12(6.5 \%)$ ageneses. There was single posterior inferior cerebellar artery in 159 (91.4\%) samples and duplicate in 10 (5.7\%), while 5 (2.9\%) specimens showed hypoplasia. The posterior inferior cerebellar artery originated from the vertebral artery in 121 (69.5\%) samples and from the basilar artery in 42 (24.1\%) samples; while in 11 (6.4\%) it originated in a common trunk with the anterior inferior cerebellar artery. In 101 (83.5\%) cases, the posterior inferior cerebellar artery originated from the intracranial segment of the vertebral artery, while $20(16.5 \%)$ samples originated from the extracranial segment. The calibres of posterior inferior cerebellar artery in its proximal and distal segments were $1.45 \pm 0.37 \mathrm{~mm}$ and $1.33 \pm 0.31 \mathrm{~mm}$, respectively.

Conclusions: This study, carried out in cadaveric material, provides relevant qualitative and morphometric information of the posterior inferior cerebellar artery, useful for the diagnosis and clinical management, as well as for the surgical approaches that may compromise this structure. (Folia Morphol 2022; 81, 3: 559-566)

Key words: cerebellar irrigation, anatomical variation, hypoplasic agenesis, vertebro-basilar junction

\section{INTRODUCTION}

Usually, the intracranial segment of vertebral artery (VA), at its distal portion, gives rise to its last branch, the posterior inferior cerebellar artery (PICA). PICA can also originate independently from basilar artery (BA), or as a common trunk with the anterior inferior cerebellar artery (AICA). PICA irrigates the posterior inferior portion of cerebellum, the spinal dorsal territory in association with posterior spinal

Address for correspondence: F.A. Gómez-Torres, DVM, PhD(c), Department of Basic Sciences, Medicine School, Universidad Industrial de Santander, Carrera 32 \# 29-31, 68002 Bucaramanga, Colombia, tel: +57 300 2004432, e-mail: falegom@uis.edu.co

This article is available in open access under Creative Common Attribution-Non-Commercial-No Derivatives 4.0 International (CC BY-NC-ND 4.0) license, allowing to download articles and share them with others as long as they credit the authors and the publisher, but without permission to change them in any way or use them commercially. 
arteries and the spinal lateral surface in association with AICA $[3,9,19]$.

Posterior inferior cerebellar artery varies in its morphological expression related to its origin, trajectory, calibres, duplications, common trunks with AICAs, agenesis and hypoplasia. In the latter scenario, another cerebellar artery modifies its trajectory to supply PICA regions, which determines dynamic balances in irrigated areas by PICA and AICA, so that when most of the inferior surface of the cerebellum is supplied by PICA, AICA's territory is lesser than PICA's or vice versa $[7,21]$. Many authors agree to divide the trajectory of the PICA in anterior, lateral medullary, televelotonsilar and cortical spinal segments, which is very useful from the topographic and surgical point of view $[19,21]$.

Posterior inferior cerebellar artery originated from the VA in $57.1-85 \%$ of cases, with lower incidences from the BA, internal carotid and posterior meningeal artery. PICA can present itself duplicated in $0.9 \%$ to $10 \%[14,17,19,20]$. Some authors described the presence of a main trunk in $75-92 \%$ cases that bifurcates into the rostral or medial and lateral or caudal branches $[9,10,25]$. In cases of absence of the PICA, other cerebellar arteries irrigate its territories $[9,17,20]$. PICA has the most variable trajectory of the cerebellar arteries and the most complex relationship with cranial nerves. In its trajectory, it courses above the glossopharyngeal nerve in a range of $14-27.5 \%$ cases, and between the roots of the accessory nerve in $20-38 \%$ of cases; while in $5-23.8 \%$ of cases crosses the fibres of the apparent origin of the vagus nerve and in $21.4-32.5 \%$ of cases passes between the vagus and accessory nerves $[9,11,19,22]$.

The relevance of PICA is related to the possibility of thromboembolic occlusions with consequent effects ranging from silent occlusion to infarct of the cerebellum or medulla oblongata with oedema, haemorrhage, and death $[9,22]$. Moreover, this artery could be affected by neurovascular compression syndromes such as glossopharyngeal neuralgia and hemifacial spasm $[2,13]$.

The anatomical characteristics of PICA have been evaluated in some population groups through the infusion of its vascular beds, classic dissection, or imaging studies $[1,4,5,9,10,14,17,19,22]$. The variant expressions of PICA with its great functional and clinical significance, makes the morphological study of these structures necessary in samples of population groups such as the mestizo (Caucasian and Native American descent), predominant in Latin America. For this rea- son, the work done supplies in a relevant fashion new reference information in our mestizo population.

\section{MATERIALS AND METHODS}

Posterior inferior cerebellar artery of 93 unclaimed bodies were studied, who underwent autopsy at the Institute of Legal Medicine and Forensic Sciences in Bucaramanga, Colombia. The inclusion criteria of the evaluated sample were mestizo (Caucasian and Native American descent) and men aged between 18 and 75 years old. The exclusion criteria included death due to traumatic brain injury or pathologies related to the encephalon. The ethics committee of the "Universidad Industrial de Santander" approved this investigation; the study complied with Resolution 008430 of 1993, Decree 2164 of 1992 and Law 10 of 1990 of the local Ministry of Health and with the principles of the Declaration of Helsinki (1964) and all subsequent revisions.

Each cadaveric specimen was subjected to bilateral channelling of the proximal segments of the vertebral arteries; through these vessels it was performed a lavage and presetting of the brain with formaldehyde $3 \%$. Thereafter, the vertebral arteries were injected with $100 \mathrm{~mL}$ of semi-synthetic resin (a mixture of Palatal E2 $10^{\circledR}$ BASF $80 \mathrm{~mL}$ and Styrene $20 \mathrm{~mL}$ ) dyed with mineral red. After 30 minutes, once obtained the resin polymerisation, the exeresis of the encephalon was performed. Then, the anatomical pieces were subjected to a formaldehyde $10 \%$ fixation for 15 days.

Afterwards, the block resection of brainstem and cerebellum was performed and the leptomeninges were released using microdissection instruments, procedure that made possible the identification of the vertebrobasilar system and each of its structures. The different morphological expressions of PICAs were recorded in relation to their presence, level of origin, calibres, trajectories, anastomosis and relations to cranial pairs according to the criteria or patterns determined by Rhoton [20]. A difference equal or greater than $0.5 \mathrm{~mm}$ was established as criteria for left or right-side arterial dominance [18]. A digital calibrator (Mitotuyo ${ }^{\circledast}$ ) was used for all morphometric evaluations of these vessels.

Digital photographs were taken from all pieces with a professional camera Canon ${ }^{\circledR} \mathrm{T} 2 \mathrm{i}$. The obtained data was registered in Excel spreadsheets and statistical analyses were carried out using Stata 8.0 software. For data analysis, the continuous variables were described using means and deviations and the 


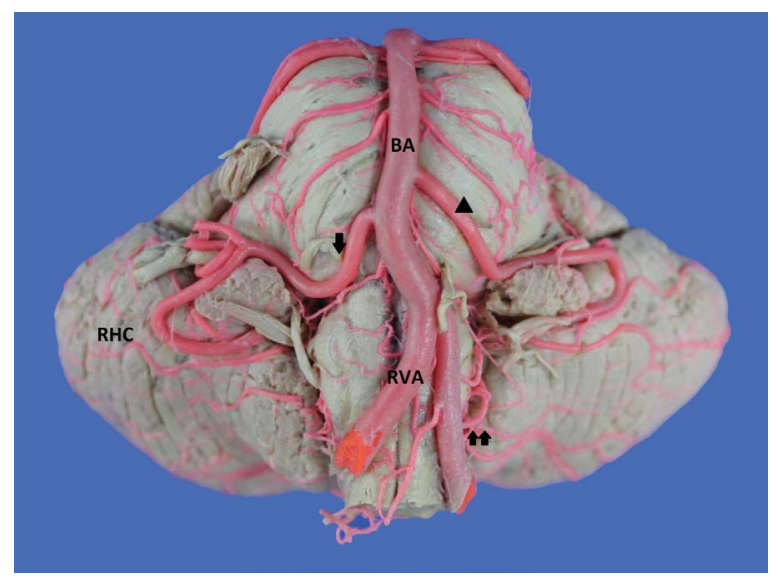

Figure 1. Front view of cerebellum. A hypoplastic left posterior inferior cerebellar artery and agenesic right one is observed. Bilateral dominance of the anterior inferior cerebellar artery; BA — basilar artery; RVA — right vertebral artery; RHC — right cerebellar hemisphere; triangular asterisk — left antero inferior cerebellar artery; arrow - right inferior anterior cerebellar artery; double arrow hypoplastic left posterior inferior cerebellar artery.

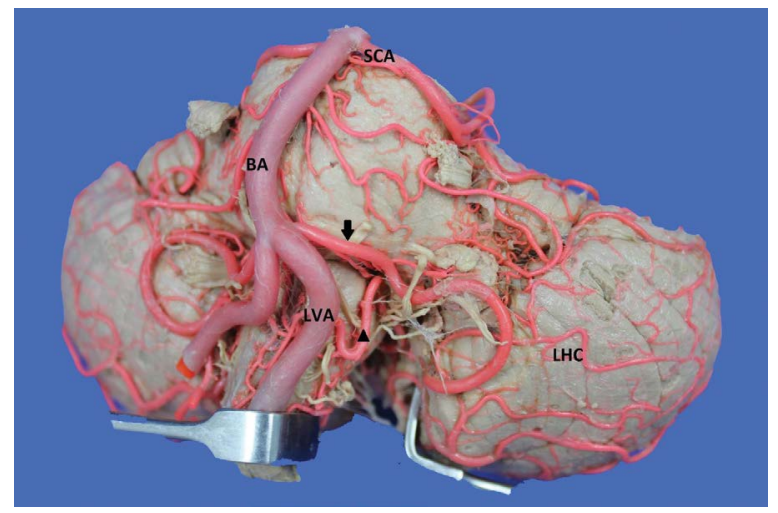

Figure 2. Front view of left cerebellar hemisphere. Posterior inferior cerebellar artery is duplicated with its origin in the vertebro-basilar junction (larger calibre) and vertebral artery; BA — basilar artery; LVA — left vertebral artery; LHC — left cerebellar hemisphere; SCA - superior cerebellar artery; arrow — inferior posterior cerebellar artery originating from the proximal segment of the basilar artery; triangular asterisk - left inferior cerebellar artery originating from the basilar artery.

nominal variables were described using its ratios. Statistical tests included $\chi^{2}$ and t-test, accepting a significance level of $p \leq 0.05$.

\section{RESULTS}

In the 93 blocks of brainstem and cerebellum evaluated, 174 (93.5\%) PICA were found, 88 on the right side and 86 on the left side. Also, there were 12 (6.5\%) ageneses (Fig. 1). There was single PICA in 159 (91.4\%) samples and duplicate in 10 (5.7\%) samples (Fig. 2), all without statistically significant difference

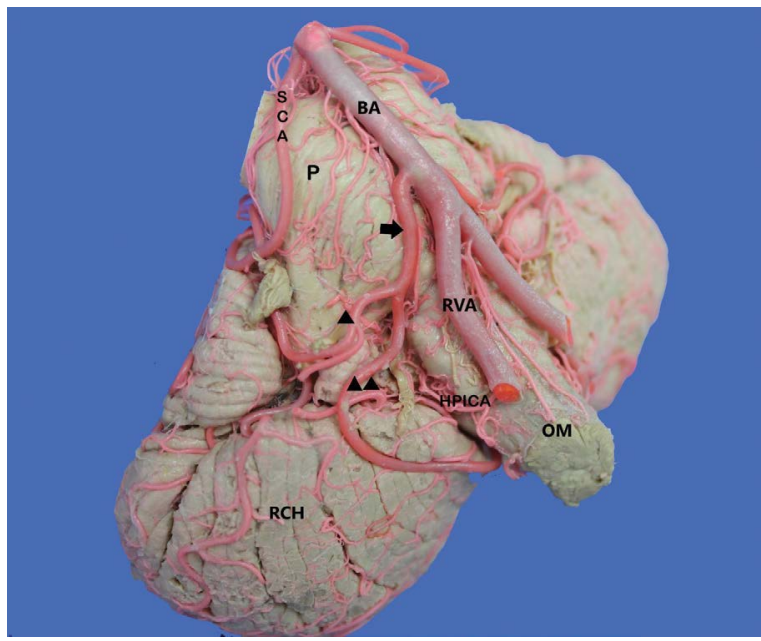

Figure 3. Front view of right cerebellar hemisphere. Posterior and anterior inferior cerebellar arteries' trunks emerging from the basilar artery (BA). Additionally, a hypoplastic posterior inferior cerebellar artery originating from the vertebral artery; $\mathrm{P}$ - pons; arrow trunk emerging from the basilar artery; triangular asterisk — inferior anterior cerebellar artery; double triangular asterisk — inferior posterior cerebellar artery; HPICA — hypoplastic posterior inferior cerebellar artery; SCA — superior cerebellar artery.

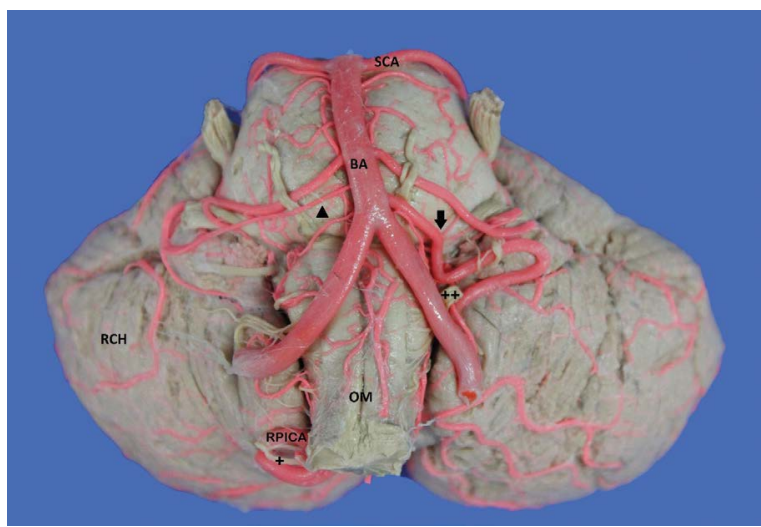

Figure 4. Anterior view of cerebellum. Left posterior inferior cerebellar artery originated from basilar artery (BA), its curse between the vagus and accessory nerves. Right posterior inferior cerebellar artery is originating from the vertebral artery's extraspinal segment relating to the spinal root of accessory nerve; $\mathrm{RCH}$ — right cerebellar hemisphere; $\mathrm{OM}$ - medulla oblongata; SCA — superior cerebellar artery; arrow — left posterior inferior cerebellar artery; RPICA - right posterior inferior cerebellar artery; + : spinal root of the accessory nerve; ++ : vagus nerve.

in relation to either presentation side $(p=0.17)$. Five (2.9\%) specimens showed hypoplasic PICAs.

In $121(69.5 \%)$ cases, PICA originated from the VA, while in $42(24.1 \%)$ cases it emerged from the BA. A common trunk between PICA and AICA was observed from the VA in 7 (4.1\%) samples (Fig. 3) and from the BA in 4 (2.3\%) samples of blocks of brainstem and cerebellum (Fig. 4). Of the arteries with their 


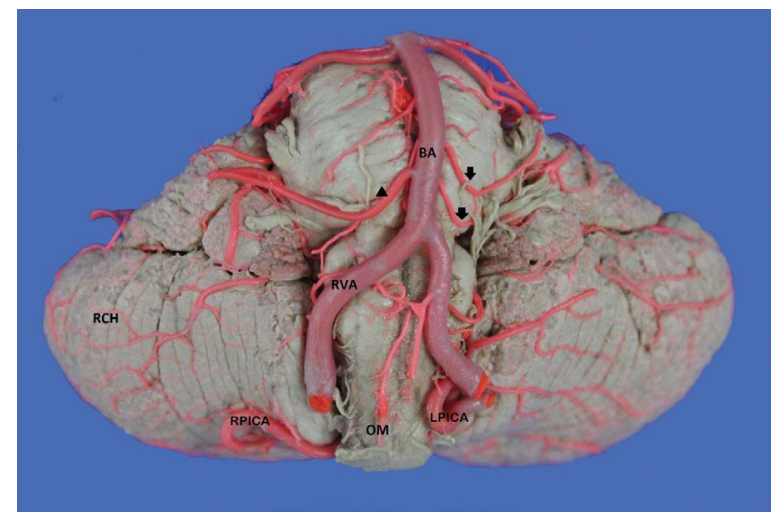

Figure 5. Anterior view of cerebellum. Bilateral origin of posterior inferior cerebellar artery from the vertebral artery's extraspinal segment. The lower loop of the tonsilomedullary segment is related with the tonsils' inferior surface; BA - basilar artery; $\mathrm{OM}$ - medulla oblongata; $\mathrm{RCH}$ — right cerebellar hemisphere; RVA — right vertebral artery; RPICA — right posterior inferior cerebellar artery; LPICA — left posterior inferior cerebellar artery; double arrow double left anterior inferior cerebellar artery; triangular asterisk anterior inferior cerebellar artery.

Table 1. Length and calibre of the segments of the inferior posterior cerebellar artery. Expressed in millimetres

\begin{tabular}{lcccc}
\hline & $\begin{array}{c}\text { Anterior } \\
\text { medullary }\end{array}$ & $\begin{array}{c}\text { Lateral } \\
\text { medullary }\end{array}$ & $\begin{array}{c}\text { Tonsil- } \\
\text { lomedullary }\end{array}$ & $\begin{array}{c}\text { Televelo- } \\
\text { tonsillar }\end{array}$ \\
\hline $\begin{array}{l}\text { Total } \\
\text { length }\end{array}$ & $3.39 \pm 1.70$ & $8.56 \pm 2.63$ & $21.06 \pm 7.22$ & $16.41 \pm 8.36$ \\
Right & $3.19 \pm 1.43$ & $8.41 \pm 2.70$ & $21.65 \pm 6.87$ & $16.55 \pm 7.24$ \\
Left & $3.53 \pm 1.86$ & $8.61 \pm 2.74$ & $20.64 \pm 7.49$ & $16.03 \pm 8.90$ \\
$\begin{array}{l}\text { Total } \\
\text { calibre }\end{array}$ & $1.45 \pm 0.37$ & $1.44 \pm 0.31$ & $1.33 \pm 0.31$ & $1.32 \pm 0.40$ \\
Right & $1.46 \pm 0.37$ & $1.42 \pm 0.26$ & $1.34 \pm 0.24$ & $1.27 \pm 0.22$ \\
Left & $1.45 \pm 0.32$ & $1.46 \pm 0.35$ & $1.32 \pm 0.33$ & $1.34 \pm 0.54$ \\
\hline
\end{tabular}

origin in the VA, 101 (83.5\%) were of the V4 segment and 20 (16.5\%) of the V3 segment (Fig. 5). PICAs which originated from the VA did so at $16.65 \pm 6.16 \mathrm{~mm}$ from the vertebro-basilar junction, while the distance to that point from those originating from the BA was $12.25 \pm 4.59 \mathrm{~mm}$, with no statistically significant differences in relation to the either presentation side ( $p=0.67)$. In $63(36.2 \%)$ samples, the PICA originated from the posterior lateral surface of the VA and BA, from lateral surface in 68 (39.1\%) samples, from posterior and posterior medial surface in 37 (21.3\%) samples and 6 (3.4\%) specimens, respectively.

Posterior inferior cerebellar artery distributed through the periphery of the medulla oblongata and the cerebellar vermis and then divided into four segments with variable length, between 1.95 to $39.23 \mathrm{~mm}$.
The segments with a short length were the anterior and lateral medullary, while the tonsillomedullary segment with its sinuous trajectory presented greater length. PICA presented a calibre of $1.45 \pm 0.37 \mathrm{~mm}$; there was no statistically significant difference in relation to either side $(p=0.27)$. A reduction of $7.6 \%$ was observed between the calibre of the medullary (mesencephalic pons) and the tonsillomedullary (mesencephalic cerebellum) segments (Table 1).

Right PICAs' calibre was higher than the left side in $74(42.5 \%)$ samples. The left branch presented a dominant calibre in $70(40.2 \%)$ cases; there was no difference in calibre in 30 (17.2\%) cases. In 141 (81\%) samples, there was a bifurcation between the lateral and medial branches, while in 33 (19\%) PICAs the branches emerged in form of a cluster, this presents a statistically significant difference $(p=0.02)$.

Lateral branches presented a calibre of $1.08 \pm$ $\pm 0.18 \mathrm{~mm}$ and the medial $0.96 \pm 0.19 \mathrm{~mm}$ $(p=0.07)$. From these branches, collaterals emerged for the cerebellar cortex, vermis and the fourth ventricle branches. A pair of cortical arteries emerged in $69(48.9 \%)$ cases from the lateral branch and three collateral arteries were observed as part of 67 (47.5\%) medial branches (Table 2).

The lower loop of the tonsillomedullary segment related to the tonsil on 148 (85.1\%) samples. In relation to the upper surface of the tonsil, it was found in $38(25.6 \%)$ cases, with the lower segment in 56 (37.9\%) and with the middle segment in 54 (36.5\%) sample blocks of brainstem and cerebellum. In 26 (14.9\%) cases the lower loop of the third segment was below the cerebellar tonsil and corresponded to the arteries that originated from V3 or from the lower part of V4 (Fig. 5).

The distance between the bifurcation point and the origin of PICA was variable; thus, it was classified in four groups every $20 \mathrm{~mm}$ : group $1-2$ (1.4\%) samples with a length of up to $20 \mathrm{~mm}$; group $2-41$ (29.1\%) samples with a length between 21 and $40 \mathrm{~mm}$; group $3-75$ (53.2\%) samples with a length between 41 and $60 \mathrm{~mm}$; group $4-23(16.3 \%)$ samples with a length equal or above $60 \mathrm{~mm}$.

We observed a variable course of PICAs with different contact points on the cranial nerves. PICA presented the following relationships to cranial nerve pairs: above glossopharyngeal in 18 (10.1\%) samples (Fig. 2); between glossopharyngeal and vagus in $12(7.2 \%)$; between vagus and accessory 49 (28.3\%) (Fig. 4); posterior to roots of the accessory nerve in 44 (25.4\%) 
Table 2. Collateral distribution by lateral and medial branch of the inferior posterior cerebellar artery

\begin{tabular}{|c|c|}
\hline Lateral branch & Medial branch \\
\hline \multirow{3}{*}{$\begin{array}{l}1 \text { cortical: } \\
6(4.3 \%)\end{array}$} & 1 collateral: 15 (10.6\%) arteries: \\
\hline & 11 vermian \\
\hline & 4 cortical \\
\hline \multirow{5}{*}{$\begin{array}{l}2 \text { cortical: } \\
69(48.9 \%)\end{array}$} & 2 collateral: 31 (22\%): \\
\hline & 20 cortical and vermian \\
\hline & 7 double vermian \\
\hline & 2 vermian and televelo \\
\hline & 2 vermian and amygdala \\
\hline \multirow{3}{*}{$\begin{array}{l}3 \text { cortical: } \\
56(39.7 \%)\end{array}$} & 3 collateral: 67 (47.5\%): \\
\hline & 65 cortical, vermian and televelo \\
\hline & 2 amygdala, vermian and televelo \\
\hline \multirow{8}{*}{$\begin{array}{l}4 \text { cortical: } \\
10(7.1 \%)\end{array}$} & 4 collateral: $15(10.6 \%)$ : \\
\hline & $\begin{array}{l}8 \text { cortical, vermian and televelo, more } \\
\text { contralateral cortical }\end{array}$ \\
\hline & $\begin{array}{l}7 \text { cortical, vermian and televelo, more } \\
\text { vermian contralateral }\end{array}$ \\
\hline & 5 collateral: 8 (5.7\%): \\
\hline & $\begin{array}{l}6 \text { cortical, vermian and televelo, more } \\
\text { cortical and contralateral vermian }\end{array}$ \\
\hline & $\begin{array}{l}2 \text { cortical, vermian and televelo, televelo } \\
\text { and contralateral vermian }\end{array}$ \\
\hline & 6 collateral: 5 (3.5\%): \\
\hline & $\begin{array}{l}5 \text { cortical, vermian and televelo, more cortical, } \\
\text { vermian and contralateral televelo }\end{array}$ \\
\hline
\end{tabular}

samples (Fig. 4); through the roots of the vagus and accessory nerves in $14(8 \%)$ and $37(21 \%)$ samples, respectively. Hypoglossal contact was observed in 91 (52.3\%) cases, 52 (57.1\%) run below to the cranial pair, $8(8.8 \%)$ above and 31 (34.1\%) samples were distributed between the roots of the pair.

\section{DISCUSSION}

Of the cerebellar arteries, the PICA is the one that presents the greatest variability. The incidence of agenesis observed in this series $(6.5 \%)$ is in accordance with some previous reports $[10,20]$. Special attention is drawn to the high incidence (35.6\%) reported by Akgun et al. [1] and no case of agenesis is reported in other studies $[9,14]$. The presence of duplicate PICA reported in the literature in a range of $2.5-10 \%[14,18,20,24,26]$ is concordant with our findings, while Macchi et al. [10] do not report duplications. In other studies, PICA hypoplasia has been reported in a range of $5-16 \%[9,20]$, a figure that is higher than that found in our series.

The origin of the PICA from the VA has been reported in a range of $72-85 \%[9,10,14,19,20,26]$, while in this study a lower incidence was found, concordant with Akgun et al. [1], whereas the origin of the PICA from the extradural segment of the VA that has been reported in $10-16.7 \%$ is concordant with what was observed in this study $[1,18,19]$. High incidence of extradural origin of the PICA reported by Macchi et al. [10] (32.5\%) and the non-report of Ucerler et al. [26] of this morphological expression is highlighted.

The significant incidence of PICA that emerges from BA should be considered; our findings are consistent with the reports of Mercier et al. [14] and Macchi et al. [10]. Other authors report this origin in a range of $7.4-12.5 \%[1,24,27]$. A PICA variable that besides being visually attractive is accompanied by marked clinical implications that determine its obstruction or injury, for its extensive irrigated territory, is the presence of PICA-AICA trunk, reported by some authors in $12.5-22 \%[4,10,14]$, whereas our observations $(6.4 \%)$ are concordant with Ucerler et al. [26]. The distance of the emergence of the PICA in relation to the vertebro-basilar junction, indicated in previous studies in 16-16.9 mm, and without significant differences in relation to the presentation side, is concordant with that found in this series. Pai et al. [17] report a distance of $12 \mathrm{~mm}$. In this study, a calibre of the anterior segment of the PICA of $1.45 \mathrm{~mm}$ was reported, similar to the figures most reported in literature $[9,18]$, while other authors denote this calibre in a range of $1.67-2 \mathrm{~mm}[1,3,7,9,16,20]$.

The large qualitative and morphometric variability observed in the various PICA studies is probably due to factors such as the size of the samples, the different measurement methodologies and the phenotypic expressions of each population group evaluated.

The bifurcation of the PICA in lateral and medial branches, close to the televelotonsilar fissure has been reported with high incidence in a range in which our findings are located, of $78-92.5 \%[9,10,20,27]$. In agreement with what is reported in literature, we find that the lateral branch is greater than the medial one and its calibre slightly higher than a millimetre; It supplies the middle and lateral segments of the occipital surface of the cerebellar hemisphere. Some previous studies $[9,19,20]$ indicate that the lateral 
branch provides between one and several cortical branches, while in our observations we recorded the presence of one to five cortical branches, the most frequent expression being the presence of two branches cortical $(48.9 \%)$ ). In the same sense, a medial branch that supplies the vermis and the medial portion of the cerebellar hemisphere is recorded. In this study we report as the most frequent scenario $(47.5 \%)$ that the medial branch provides cortical, vermian and televelar branches.

The location of the caudal loop of the tonsillar medullary segment below the lower pole of the tonsil occurs when the PICA emerges from the extradural portion of the VA or from the proximal part of the intracerebral segment of this artery; this condition, observed in our study at $14.9 \%$, is consistent with previous studies that report it in a range of $12.5-27.5 \%$ $[9,10,26]$. We also find this loop at the level of the pole or segment lower tonsil in a slightly higher percentage $(37.9 \%)$, as reported by some authors $[9,10,26]$. In other cases, we recorded the location of the loop in the middle and upper segments of the medial wall of the tonsil (62.1\%), incidence slightly higher than that reported by Lister et al. [9], while other studies $[10,26]$ report this expression in a range of $30-45 \%$.

The location and extent of the infarctions originated by PICA occlusion are mainly determined by the nature of its aetiology (atheromatosis vs. embolism), haemodynamic factors, the anatomic variations of the vessels and the arterio-arterial anastomosis characteristics. The anatomical variations mainly comprise the origin, the branching pattern, irrigated areas, and parent vessel sizes. For example, people with an aberrant origin of the PICA and/or hypoplasia of the VA have a greater chance of having a cerebellar infarction and if it happens, it is expected to be larger and extensive infarcts than individuals with a usual pattern of the arterial anatomy in the posterior fossa. The syndrome associated with lateral medullary infarction may be caused by occlusion of PICA or VA, but it is most commonly attributed to occlusion of the VA $[12,15,16,20,27,28]$.

The syndrome originated by the PICA occlusion is known as the lateral medullary syndrome. This syndrome is characterized by the presence of: anaesthesia and thermoanalgesia in the hemibody caused by damage to the spinothalamic tract; Ipsilateral Horner syndrome determined by the affectation of the oculosympathetic fibres in the lateral medullary reticular substance; dysphagia, dysarthria and dysphonia as a result of ipsilateral paresis of the palate, pharynx, and vocal cords caused by an injury of the ambiguous nucleus; facial ipsilateral hypoesthesia, caused by lesions on the trigeminal tract; ataxia, dizziness, nystagmus, and ipsilateral cerebellar signs caused by damage to the vestibular nuclei and arqui and paliocerebellum; emesis explained by the involvement of the nucleus of the solitary tract; nystagmus and diplopia caused by an injury to the spinal cord and the medial longitudinal fasciculus; facial paralysis caused by damage to the seventh cranial nerve motor nucleus $[6,8,16,20,28]$.

Cerebral revascularisation in the posterior circulation is well recognised as an important factor in the treatment of aneurysms that arise at the origin of the PICA, most commonly in the posterior fossa below the basilar apex, and less frequently in the distal segments [9]. The revascularisation is also used in the treatment of complex and giant intracranial tumours involving the pontocerebellar angle, occipital foramen, cervicocranial junction, clivus, jugular foramen, fourth ventricle, cerebellum and arteriovenous malformations; lesions that involve major vessels of this anatomical region. In these procedures the PICA and AICA are anastomosed end-to-end, end-to-side, or side to side to the contralateral equivalent arteries or extracranial arteries, such as the superficial temporal artery and occipital artery to achieve the neural parenchyma revascularisation $[1,7,20,23]$. Although bypass procedures can reduce mortality and morbidity, knowledge of the anatomical characteristics of the vasculature plays an important role in preoperative planning and appropriate locations for anastomosis $[1,20]$.

Our findings are consistent with that reported in previous studies $[9,10,19,20,22]$ that record the relationship of the PICA with the nerves that emerge from the medulla oblongata, being the most frequent scenario the course of the artery between pairs $X$ and XI (21-31\%), followed by the course of the artery between the fibres of the XI pair (10-27\%). The trajectory of the PICA over the IX pair is reported as the lowest incidence (4.8-17\%). Our study is consistent with the majority of reports $[10,14,20]$ that indicate that the path of the PICA with the highest incidence in its relationship with the hypoglossal nerve is the one which passes under the nerve (47.5-57.1\%), while Lister et al. [9] reports as the most frequent trajectory that of the PICA coursing between the fibres of 
the referred nerve. The dimensions of the segments of the PICA, anterior medulla $(4.4 \mathrm{~mm})$, medullary lateral $(15.4 \mathrm{~mm})$, tonsilomedullary $(24.5 \mathrm{~mm})$ and televelotonsilar (13.3 $\mathrm{mm}$ ) reported by Lister et al. [9] are similar to those recorded in this series.

The IX-XII cranial nerves are usually in contact with the posterior surface of the VA, however, with the exception of the IX, the compression syndromes associated with these nerves are rare, although the sensorial distributions of these nerves are limited compared to the trigeminal nerve. The contacts between the cranial nerves and the VA become symptomatic when occurs an elongation or tortuosity of the proximal segments of the PICA, caused by age and arteriosclerosis. The vascular contact itself might not be enough to change the myelin structure in the root entry zone. Therefore, the presence of vascular indentation in patients with spasm of these nerves could strengthen the change in the myelin sheath in root entry zone that produces symptoms $[2,13,25]$. The compression of the glossopharyngeal and vagus nerves can cause severe episodic pain lasting from a few seconds to minutes, at the level of the palatine tonsil, larynx, tongue and ear, structures innervated by somatosensory elements of these nerves emerging through the retro-olive grove [13].

\section{CONCLUSIONS}

This study, carried out in cadaveric material, provides relevant qualitative and morphometric information of the PICA, useful for the diagnosis and clinical management, as well as for the surgical approaches that may compromise this structure.

\section{Acknowledgements}

To the Institute of Legal Medicine and Forensic Sciences of Bucaramanga, Colombia, for the donation of the specimens studied in this research.

\section{Conflict of interest: None declared}

\section{REFERENCES}

1. Akgun V, Battal B, Bozkurt $Y$, et al. Normal anatomical features and variations of the vertebrobasilar circulation and its branches: an analysis with 64-detector row CT and 3T MR angiographies. Sci World J. 2013; 2013: 620162, doi: 10.1155/2013/620162, indexed in Pubmed: 24023533.

2. Chung SS, Chang JW, Kim SH, et al. Microvascular decompression of the facial nerve for the treatment of hemifacial spasm: preoperative magnetic resonance imaging related to clinical outcomes. Acta Neurochir (Wien). 2000; 142(8):
901-907, doi: 10.1007/s007010070076, indexed in Pubmed: 11086829.

3. Fine $A D$, Cardoso A, Rhoton AL. Microsurgical anatomy of the extracranial-extradural origin of the posterior inferior cerebellar artery. J Neurosurg. 1999; 91(4): 645-652, doi: 10.3171/jns.1999.91.4.0645, indexed in Pubmed: 10507387.

4. Hou K, Li G, Luan T, et al. Anatomical study of anterior inferior cerebellar artery and its reciprocal relationship with posterior inferior cerebellar artery based on angiographic data. World Neurosurg. 2020; 133: e459-e472, doi: 10.1016/j.wneu.2019.09.047, indexed in Pubmed: 31526888.

5. Isaji T, Yasuda $M$, Kawaguchi $R$, et al. Posterior inferior cerebellar artery with an extradural origin from the $V$ segment: higher incidence on the nondominant vertebral artery. J Neurosurg Spine. 2018; 28(2): 154-159, doi: 10.3 171/2017.5.SPINE161286, indexed in Pubmed: 29192876.

6. Kase CS, Norrving B, Levine SR, et al. Cerebellar infarction. Clinical and anatomic observations in 66 cases. Stroke. 1993; 24(1): 76-83, doi: 10.1161/01.str.24.1.76, indexed in Pubmed: 8418555.

7. Kawashima M, Rhoton AL, Tanriover N, et al. Microsurgical anatomy of cerebral revascularization. Part II: posterior circulation. J Neurosurg. 2005; 102(1): 132-147, doi: 10.3171/jns.2005.102.1.0132, indexed in Pubmed: 15658105.

8. Kim HA, Yi HA, Lee H. Recent advances in cerebellar ischemic stroke syndromes causing vertigo and hearing loss. Cerebellum. 2016; 15(6): 781-788, doi: 10.1007/s12311015-0745-x, indexed in Pubmed: 26573627.

9. Lister R, Rhoton A, Matsushima $T$, et al. Microsurgical anatomy of the posterior inferior cerebellar artery. Neurosurgery. 1982; 10(2): 170-199, doi: 10.1227/00006123198202000-00004.

10. Macchi V, Porzionato A, Parenti A, et al. The course of the posterior inferior cerebellar artery may be related to its level of origin. Surg Radiol Anat. 2004; 26(1): 60-65, doi: 10.1007/s00276-003-0190-2, indexed in Pubmed: 14658014.

11. Macchi V, Porzionato A, Guidolin D, et al. Morphogenesis of the posterior inferior cerebellar artery with three-dimensional reconstruction of the late embryonic vertebrobasilar system. Surg Radiol Anat. 2005; 27(1): 56-60, doi: 10.1007/s00276-004-0303-6, indexed in Pubmed: 15645157.

12. Marinković $\mathrm{S}$, Kovacević $\mathrm{M}$, Gibo $\mathrm{H}$, et al. The anatomical basis for the cerebellar infarcts. Surg Neurol. 1995; 44(5): 450-460, doi: 10.1016/0090-3019(95)00195-6, indexed in Pubmed: 8629230.

13. Matsushima T, Goto $Y$, Ishioka $H$, et al. Possible role of an endovascular provocative test in the diagnosis of glossopharyngeal neuralgia as a vascular compression syndrome. Acta Neurochir (Wien). 1999; 141(11): 1229-1232, doi: 10.1007/s007010050423, indexed in Pubmed: 10592125.

14. Mercier PH, Brassier G, Fournier HD, et al. Vascular microanatomy of the pontomedullary junction, posterior inferior cerebellar arteries, and the lateral spinal arteries. Interv Neuroradiol. 2008; 14(1): 49-58, doi: 10.1177/1591019 90801400107, indexed in Pubmed: 20557786. 
15. Min WK, Kim YS, Kim JY, et al. Atherothrombotic cerebellar infarction: vascular lesion-MRI correlation of 31 cases. Stroke. 1999; 30(11): 2376-2381, doi: 10.1161/01. str.30.11.2376, indexed in Pubmed: 10548674.

16. Murakami T, Nakayasu $H$, Doi M, et al. Anterior and posterior inferior cerebellar artery infarction with sudden deafness and vertigo. J Clin Neurosci. 2006; 13(10): 1051-1054, doi: 10.1016/j.jocn.2005.12.045, indexed in Pubmed: 17074488.

17. Pai BS, Varma RG, Kulkarni RN, et al. Microsurgical anatomy of the posterior circulation. Neurol India. 2007; 55(1): 31-41, doi: 10.4103/0028-3886.30424, indexed in Pubmed: 17272897.

18. Pekcevik Y, Pekcevik R. Variations of the cerebellar arteries at CT angiography. Surg Radiol Anat. 2014; 36(5): 455-461, doi: 10.1007/s00276-013-1208-z, indexed in Pubmed: 24061702.

19. Person $H$, Vallée $B$, Lefèvre $C$, et al. Arterial and neural relations at the posterior and lateral aspects of the medullo-spinal junction. Surg Radiol Anat. 1998; 20(3): 177-184, doi: 10.1007/BF01628892, indexed in Pubmed: 9706676.

20. Rhoton AL. The cerebellar arteries. Neurosurgery. 2000; 47(3 Suppl): S29-S68, doi: 10.1097/00006123200009001-00010, indexed in Pubmed: 10983304.

21. Rodríguez-Hernández A, Rhoton AL, Lawton MT. Segmental anatomy of cerebellar arteries: a proposed nomenclature. Laboratory investigation. J Neurosurg. 2011; 115(2):
387-397, doi: 10.3171/2011.3.JNS101413, indexed in Pubmed: 21548748.

22. Rusu MC, Popa E, Jianu AM, et al. The vascular layers on the rostral ventrolateral medulla. Rom J Morphol Embryol. 2012; 53(4): 951-956, indexed in Pubmed: 23303018.

23. Shrontz C, Dujovny M, Ausman Jl, et al. Surgical anatomy of the arteries of the posterior fossa. J Neurosurg. 1986; 65(4): 540-544, doi: 10.3171/jns.1986.65.4.0540, indexed in Pubmed: 3760965.

24. Songur A, Gonul Y, Ozen OA, et al. Variations in the intracranial vertebrobasilar system. Surg Radiol Anat. 2008; 30(3): 257-264, doi: 10.1007/s00276-008-0309-6, indexed in Pubmed: 18253692.

25. Thomas KL, Vilensky JA. The anatomy of vascular compression in trigeminal neuralgia. Clin Anat. 2014; 27(1): 89-93, doi: 10.1002/ca.22157, indexed in Pubmed: 23381734

26. Ucerler H, Saylam C, Cagli S, et al. The posterior inferior cerebellar artery and its branches in relation to the cerebellomedullary fissure. Clin Anat. 2008; 21(2): 119-126, doi: 10.1002/ca.20581, indexed in Pubmed: 18189278.

27. Urban PP. Speech motor deficits in cerebellar infarctions. Brain Lang. 2013; 127(3): 323-326, doi: 10.1016/j. bandl.2013.10.001, indexed in Pubmed: 24189047.

28. Venti M. Cerebellar infarcts and hemorrhages. Front Neurol Neurosci. 2012; 30: 171-175, doi: 10.1159/000333635, indexed in Pubmed: 22377889. 